Supplement of Geosci. Model Dev., 12, 1601-1612, 2019

https://doi.org/10.5194/gmd-12-1601-2019-supplement

(C) Author(s) 2019. This work is distributed under

the Creative Commons Attribution 4.0 License.

(c) (1)

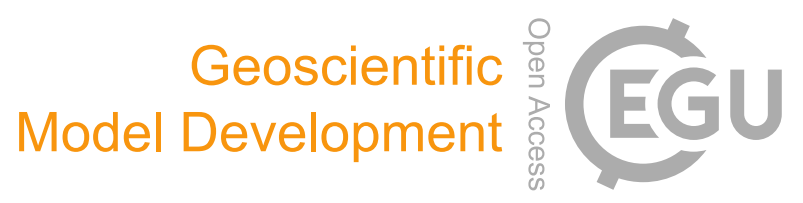

Supplement of

\title{
Evaluating the E3SM land model version 0 (ELMv0) at a temperate forest site using flux and soil water measurements
}

\author{
Junyi Liang et al. \\ Correspondence to: Junyi Liang (liangj@ornl.gov) and Gangsheng Wang (wanggs@ou.edu)
}

The copyright of individual parts of the supplement might differ from the CC BY 4.0 License. 


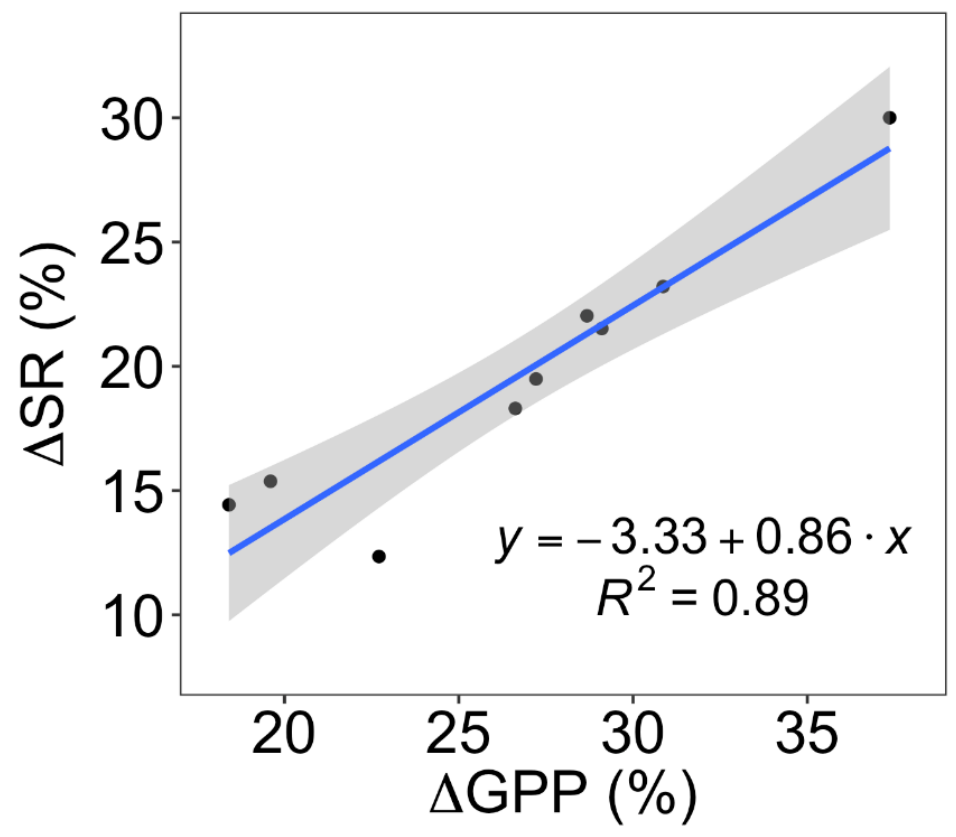

Figure S1: Relationship between changes in simulated annual soil respiration $(\Delta S R)$ and gross primary production ( $\triangle \mathrm{GPP}$ ) induced by improvement of soil water potential using the Hanson model. 

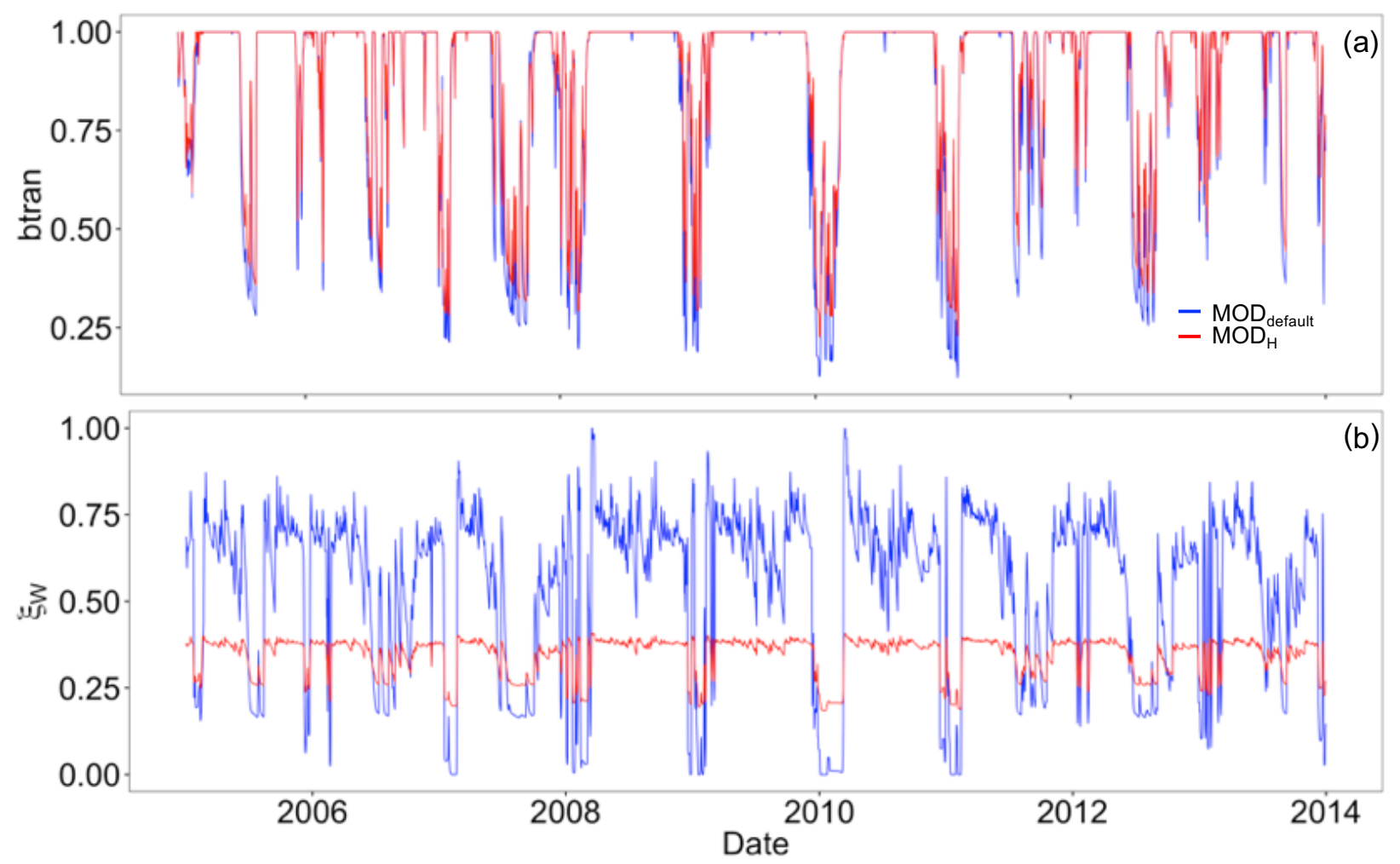

Figure S2 Impact of the changed SWP on the moisture modifiers of GPP (btran, a) and heterotrophic respiration $\left(\xi_{\mathbf{w}}, \mathbf{b}\right)$. $\mathrm{MOD}_{\text {default: }}$ model output before soil water potential improvement; $\mathrm{MOD}_{\mathrm{H}}$ : model output after soil water potential improvement using the Hanson model. 


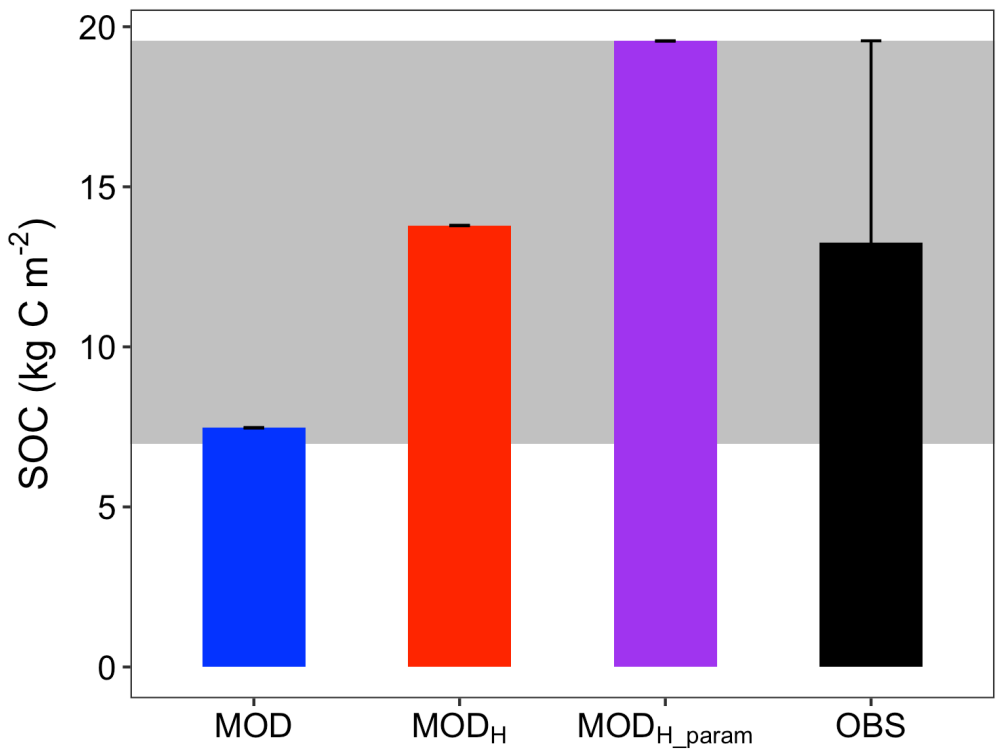

Figure S3 Comparison of the observed and modeled soil organic carbon (SOC) stocks. OBS: observation; MOD: model output before soil water potential improvement; $\mathrm{MOD}_{\mathrm{H}}$ : model output after soil water potential improvement using the Hanson model; $\mathrm{MOD}_{\mathrm{H} \_ \text {param }}$ : model output after soil water potential improvement using the Hanson model and parameter adjustments. 


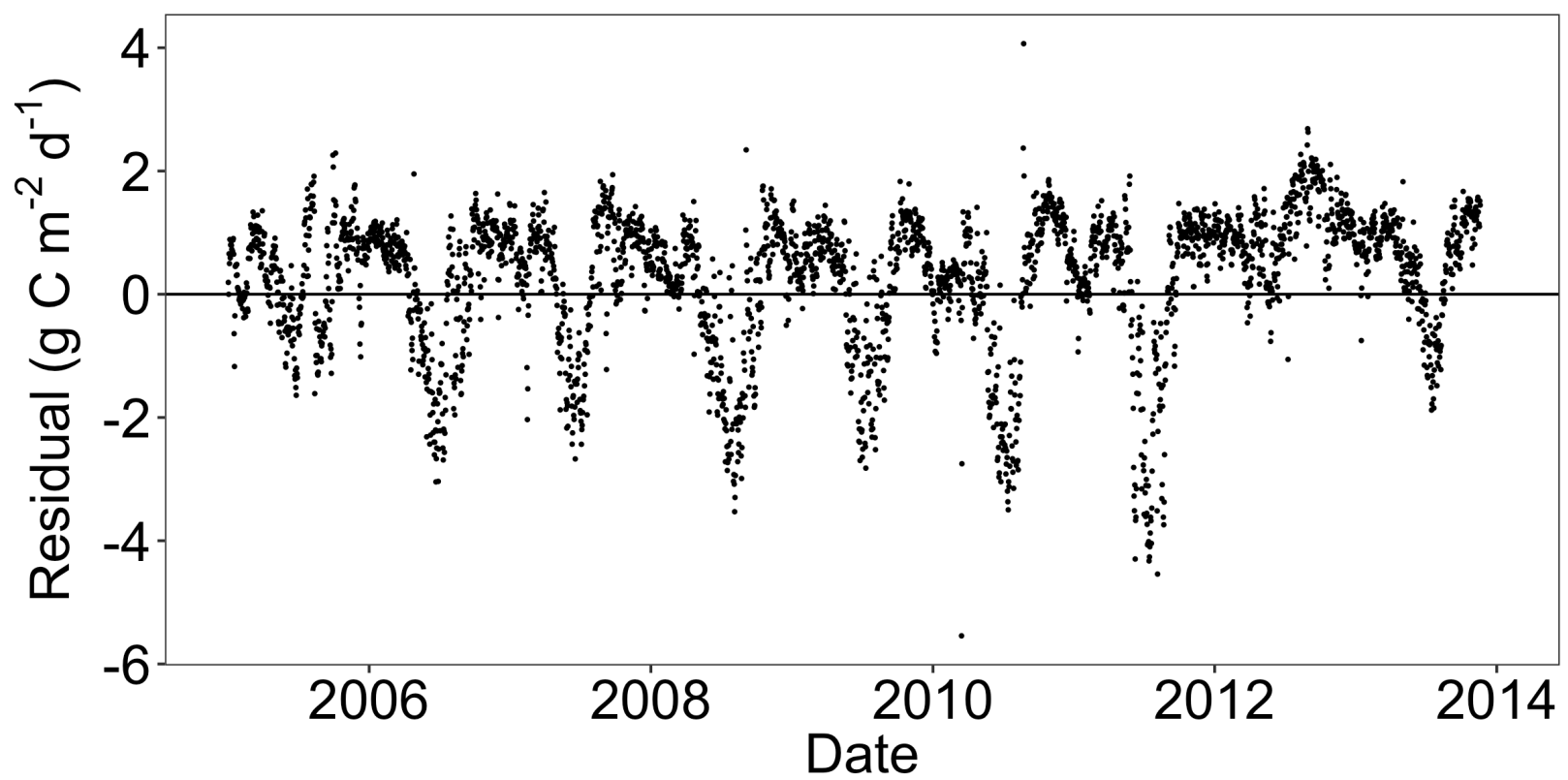

Figure S4. Residual (modeled - observed) of soil respiration (SR) from 2005 to 2013. The respective negative and positive residuals indicate that the E3SM underestimated SR during peak growing seasons and overestimated SR during other seasons. 

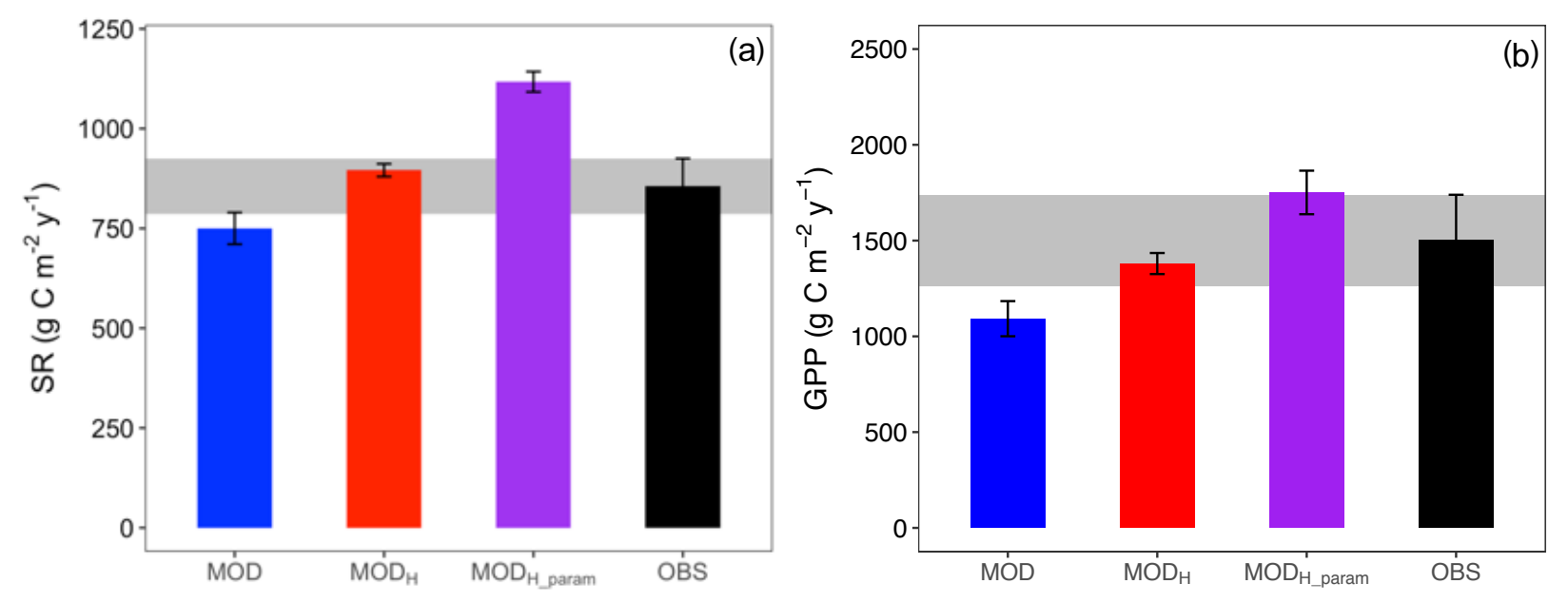

Figure S5 Comparison of the observed and modeled soil respiration (SR) and gross primary production (GPP). OBS: observation; MOD: model output before soil water potential improvement; $\mathrm{MOD}_{\mathrm{H}}$ : model output after soil water potential improvement using the calibrated Hanson model; $\mathrm{MOD}_{\mathrm{H} \_ \text {param: }}$ model output after soil water potential improvement using the calibrated Hanson model and parameter adjustments. 

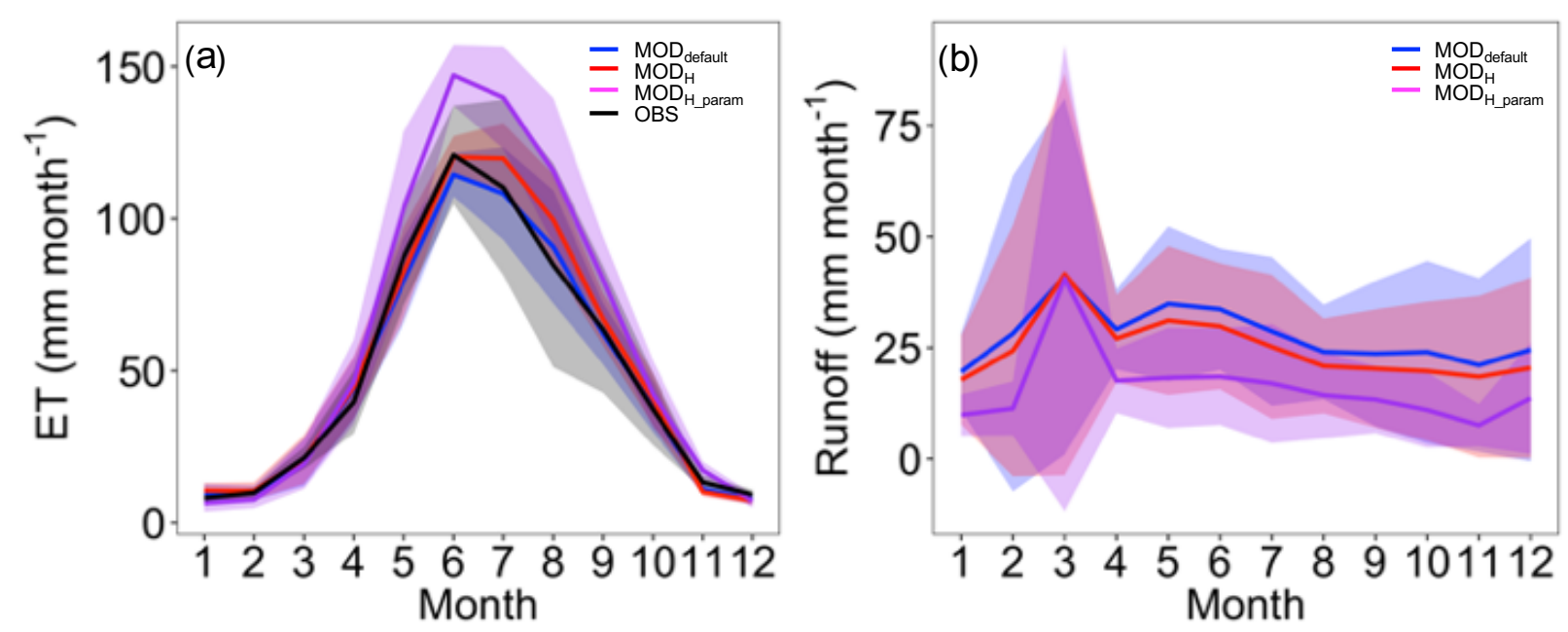

Figure S6 Modeled evapotranspiration (ET) and runoff in response to the improved SWP and parameter adjustments. OBS: observation; $\mathrm{MOD}_{\text {default: }}$ model output before soil water potential improvement; $\mathrm{MOD}_{\mathrm{H}}$ : model output after soil water potential improvement using the Hanson model; $\mathrm{MOD}_{\mathrm{H} \_ \text {param: }}$ model output after soil water potential improvement using the Hanson model and parameter adjustments. 

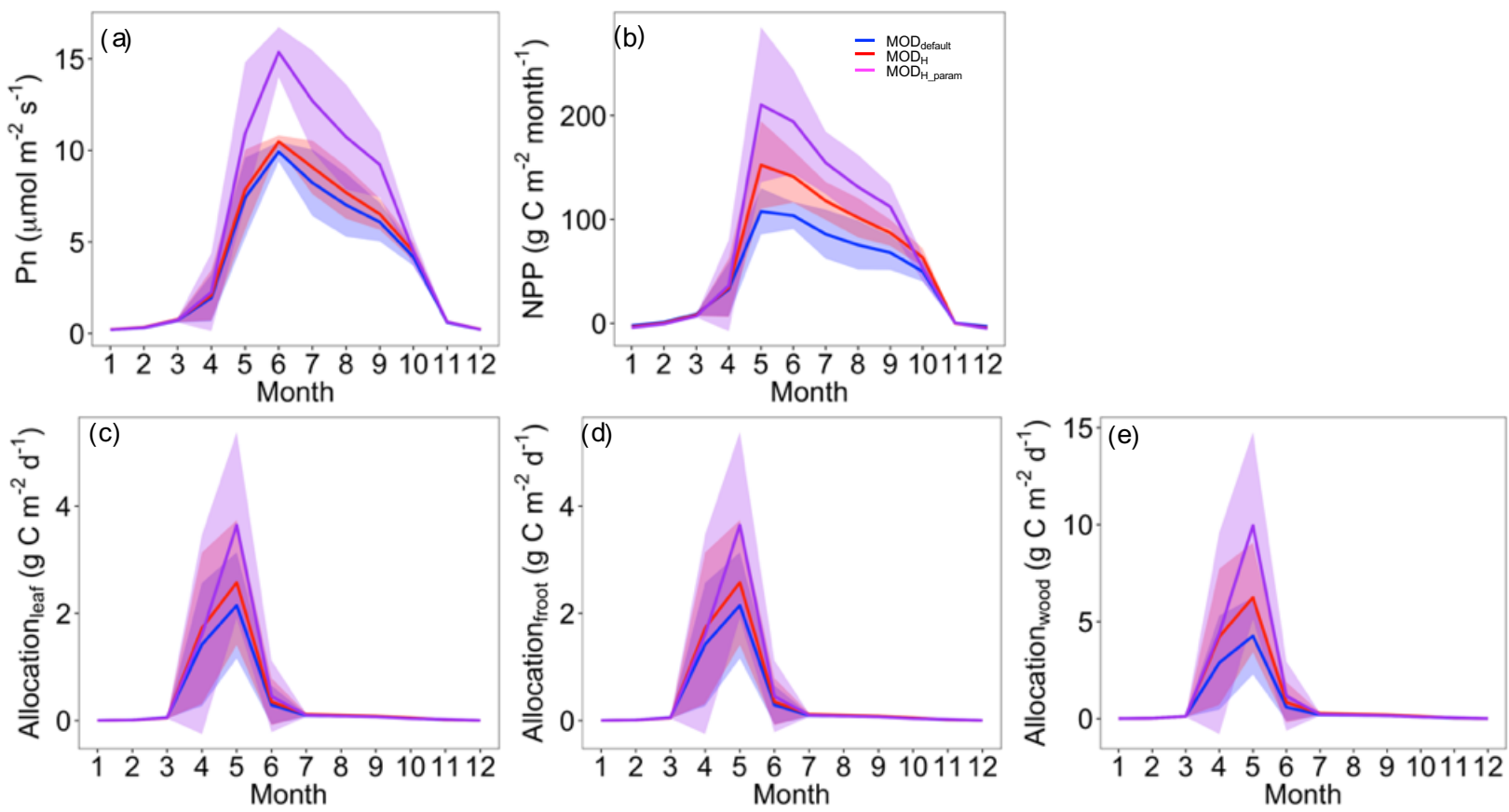

Figure S7 The annual mean cycles of photosynthesis (Pn), net primary production (NPP) and $\mathrm{C}$ allocations to fine root (Allocation $_{\text {froot }}$, leaf (Allocation leaf $_{\text {) }}$ and woody tissue (Allocation $_{\text {wood). }}$ MOD default: model output before soil water potential improvement; MOD $_{\mathrm{H}}$ : model output after soil water potential improvement using the Hanson model; MOD ${ }_{\mathrm{H} \_ \text {param: }}$ model output after soil water potential improvement using the Hanson model and parameter adjustments. 

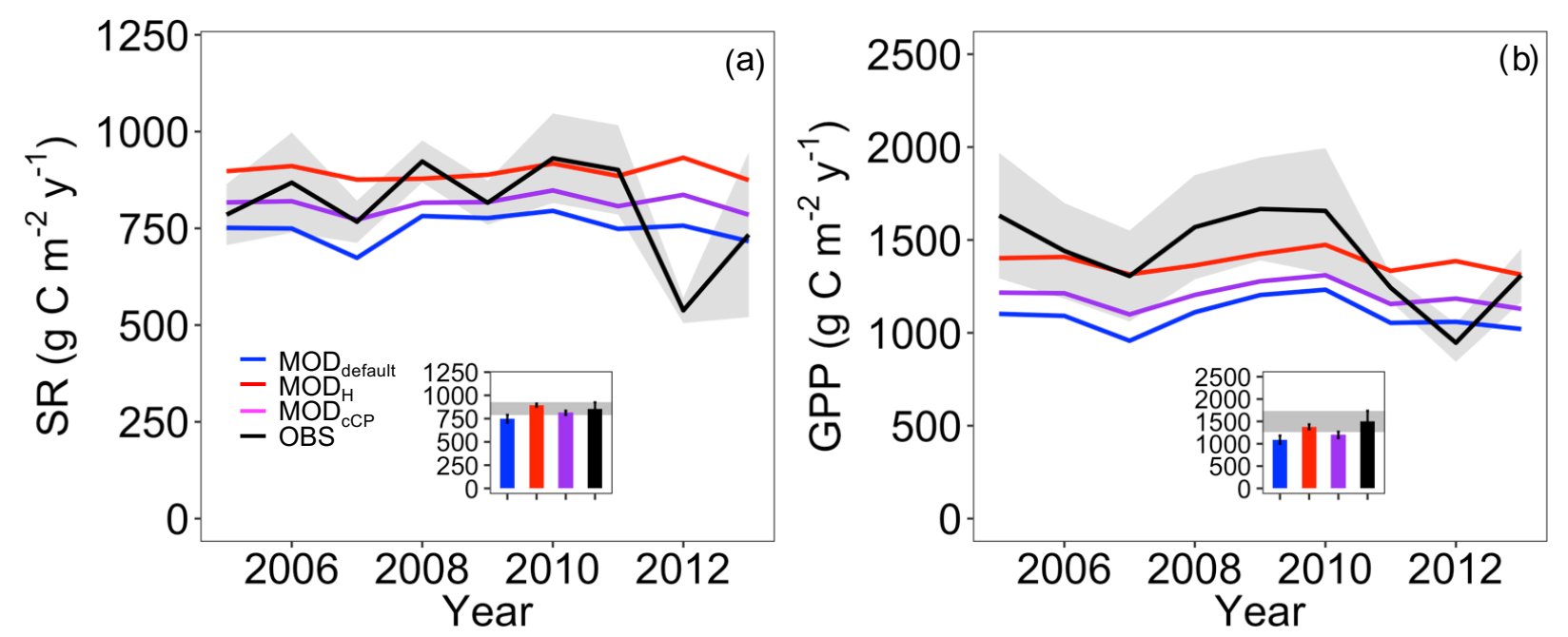

Figure S8: Annual soil respiration (SR) and gross primary production (GPP). Blue lines are the ELMv0 simulations with default parameters (MOD default), red lines with the soil water potential improved using the calibrated Clapp \& Hornberger model $\left(\mathrm{MOD}_{\mathrm{cCP}}\right)$, and purple lines with the soil water potential improved using the Hanson model $\left(\mathrm{MOD}_{\mathrm{H}}\right)$. Black lines and grey area are the observed (OBS) mean and 1 sigma range, which were calculated from eight field replications for SR, and from three different net ecosystem exchange partitioning methods for GPP. The inserted bar plots are mean annual average \pm 1 sigma across 2005-2011. 

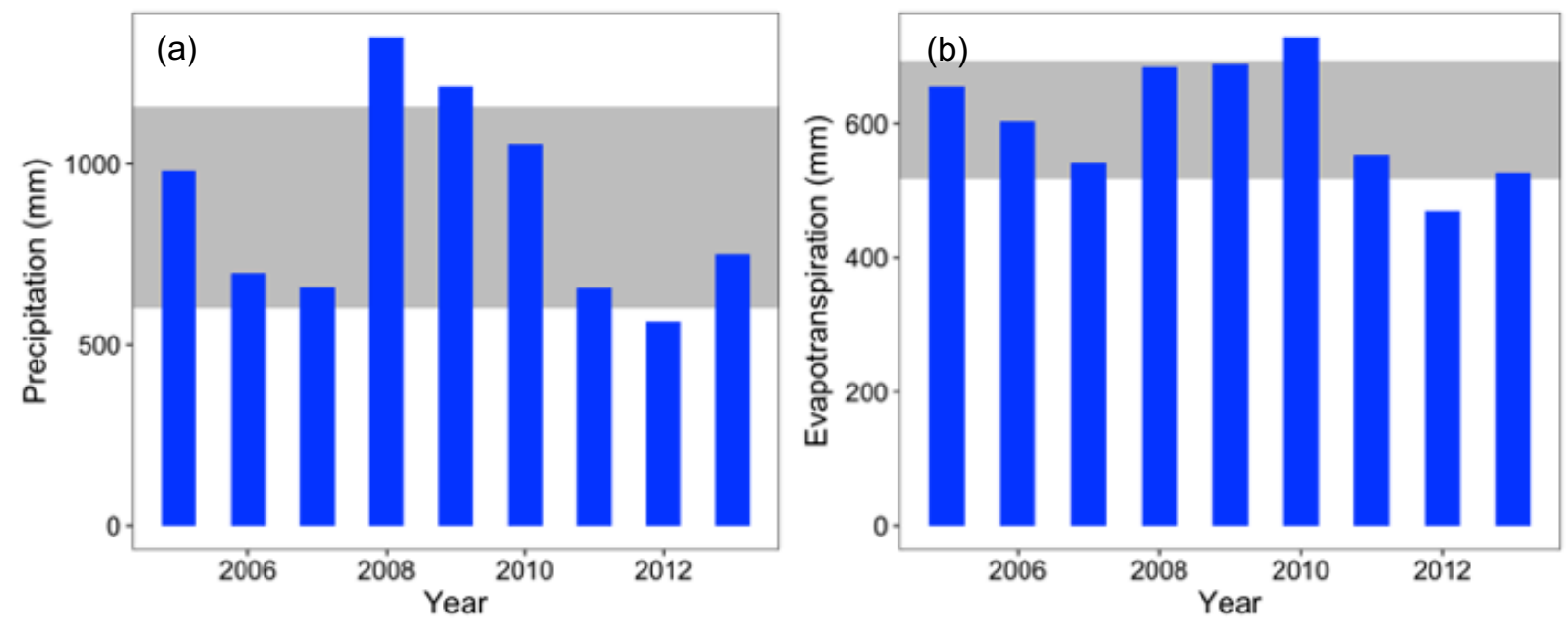

Figure S9. Mean annual precipitation and evapotranspiration at the MOFLUX site from 2005 to 2013. Both precipitation and evapotranspiration were lower in 2012 than other years. The grey bars show the multi-year standard deviation. 

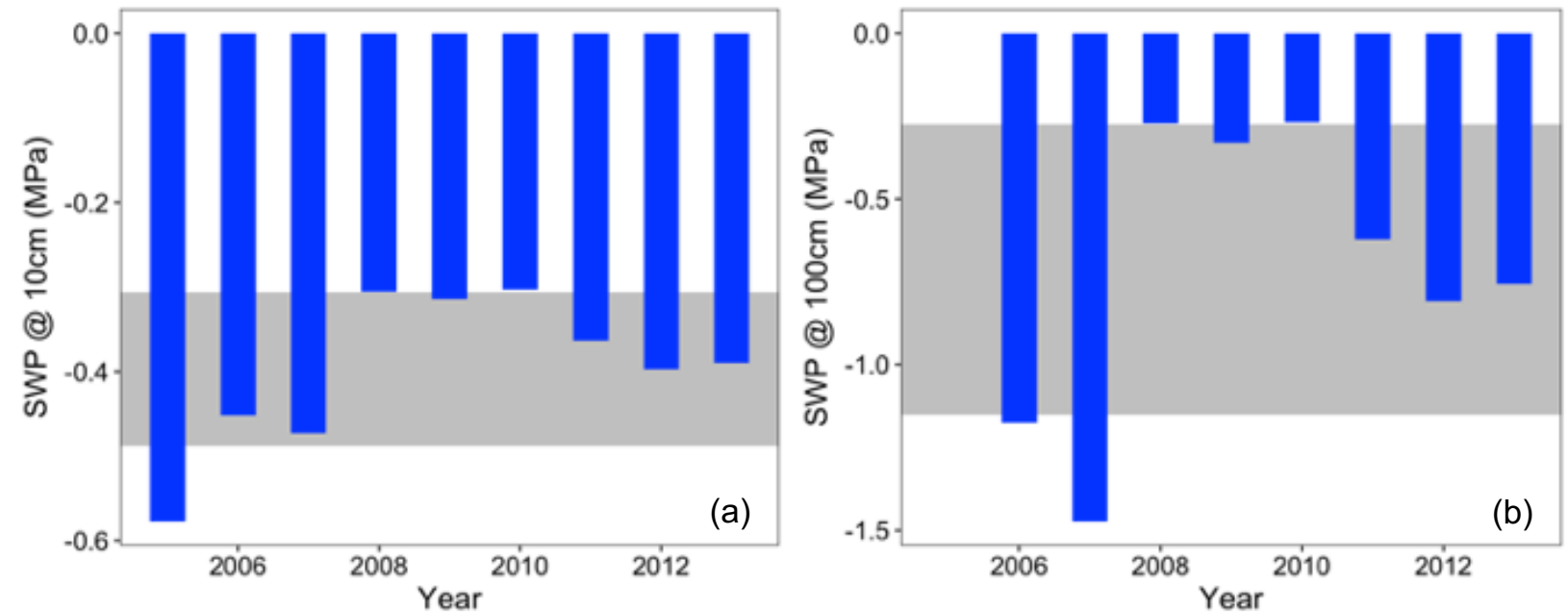

Figure S10. Mean annual soil water potential (SWP) at $10 \mathrm{~cm}$ and $100 \mathrm{~cm}$ at the MOFLUX site. The grey bars show the multi-year standard deviation. 

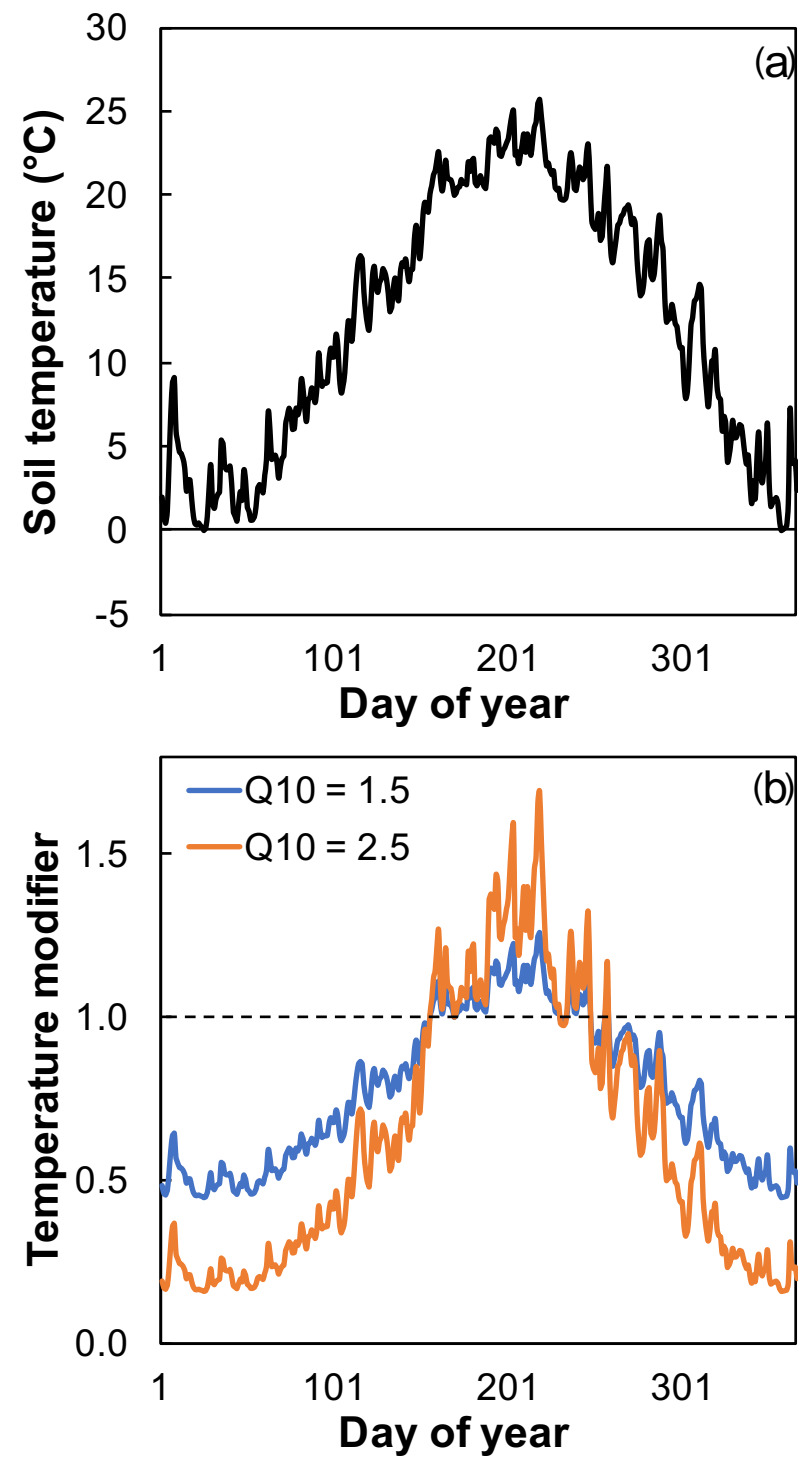

Figure S11. An example showing the effect of $Q_{10}$ on the seasonality of soil heterotrophic respiration. a, soil temperature; $\mathbf{b}$, temperature modifier on soil heterotrophic respiration with $\mathrm{Q}_{10}$ of 1.5 (blue) and 2.5 (orange). 


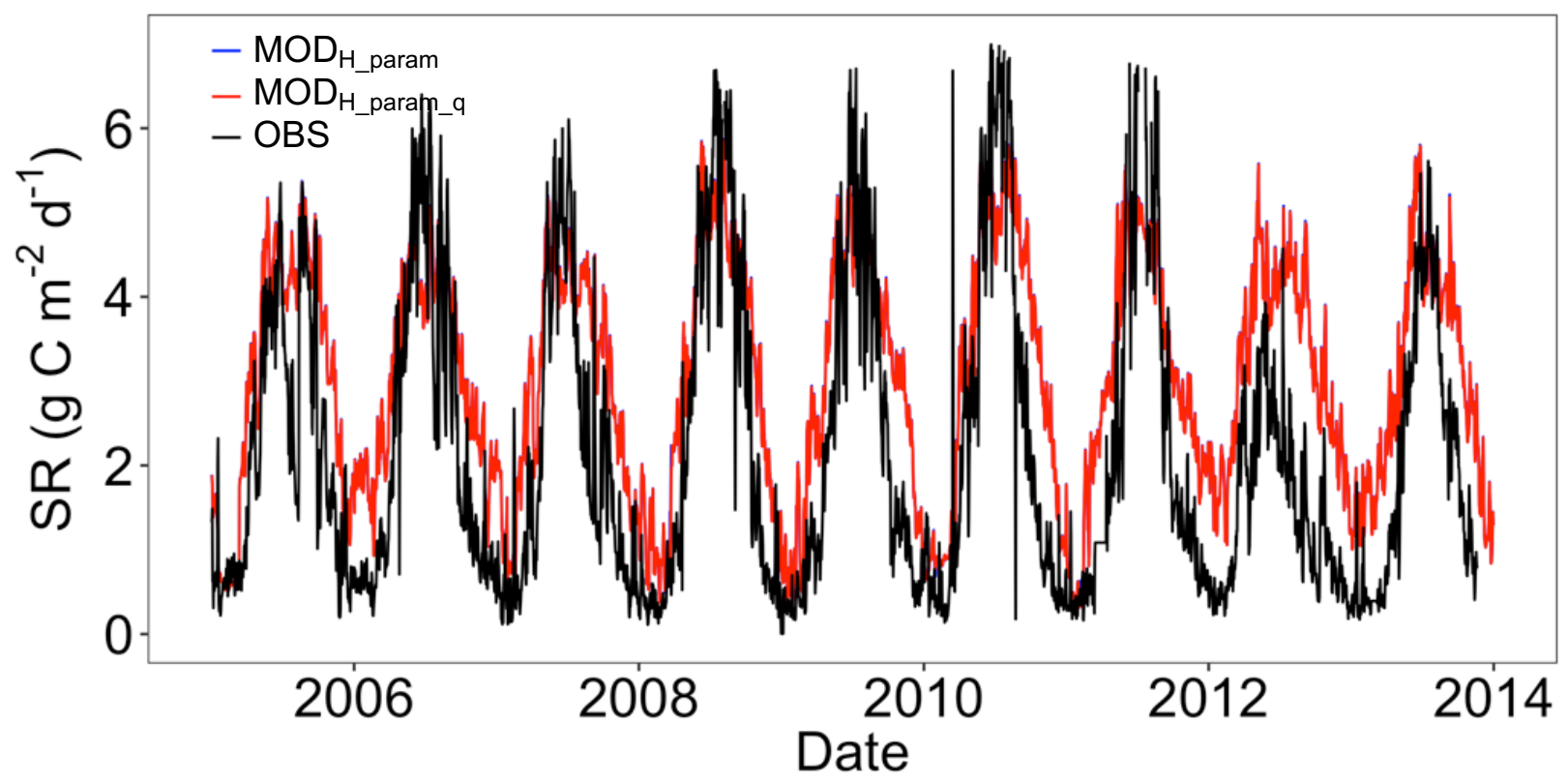

Figure S12. Effect of $\mathbf{Q}_{10}$ modification on soil respiration (SR). OBS: observation;

$\mathrm{MOD}_{\mathrm{H} \_ \text {param: }}$ model output after soil water potential improvement and parameter modification but with the default $\mathrm{Q}_{10}$ value (i.e., 1.5); $\mathrm{MOD}_{\mathrm{H} \_ \text {param_q }}$ : model output after soil water potential improvement and parameter modification with modified $\mathrm{Q}_{10}$ (i.e., 2.5). The blue and red lines are almost overlap with each other, indicating that changing $\mathrm{Q}_{10}$ resulted in little change in SR. 